\title{
Triarylphosphonium Salts as Radical Precursors Using Photoredox Catalysis
}

Andrew Boldt, Jonathan Ramirez, and Susan Stevenson* Department of Chemistry, Carthage College 2001 Alford Park Drive, Kenosha WI 53140

CARTHAGE COLLEGE

\section{Background}

- Traceless Activation Groups (TAGs) are currently studied with the use of photoredox catalysis conditions as an approach to access carbon radicals.

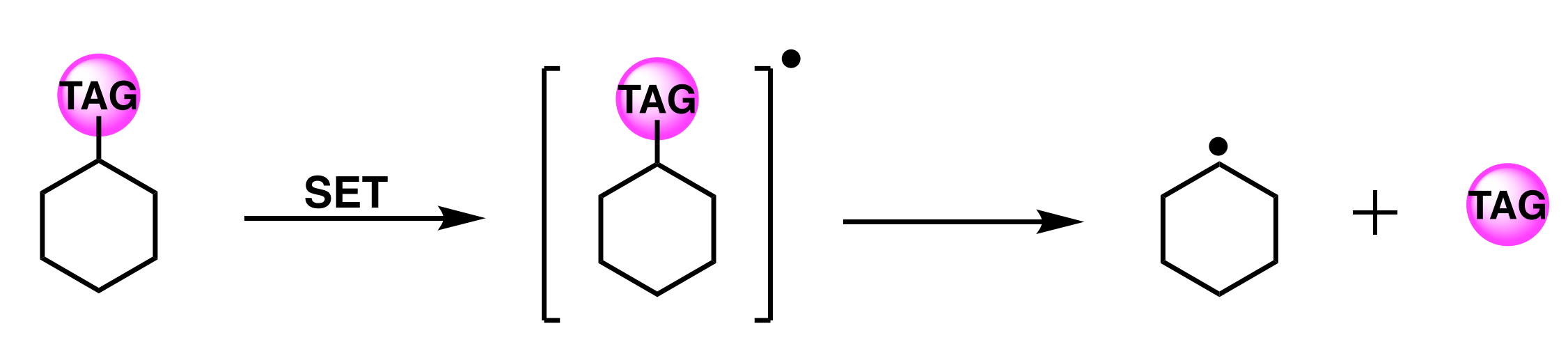

Some previous reserch that has been conducted on the rectivity of specific TAGs such as phthalimides and $N$ hydroxphthelmide esters.

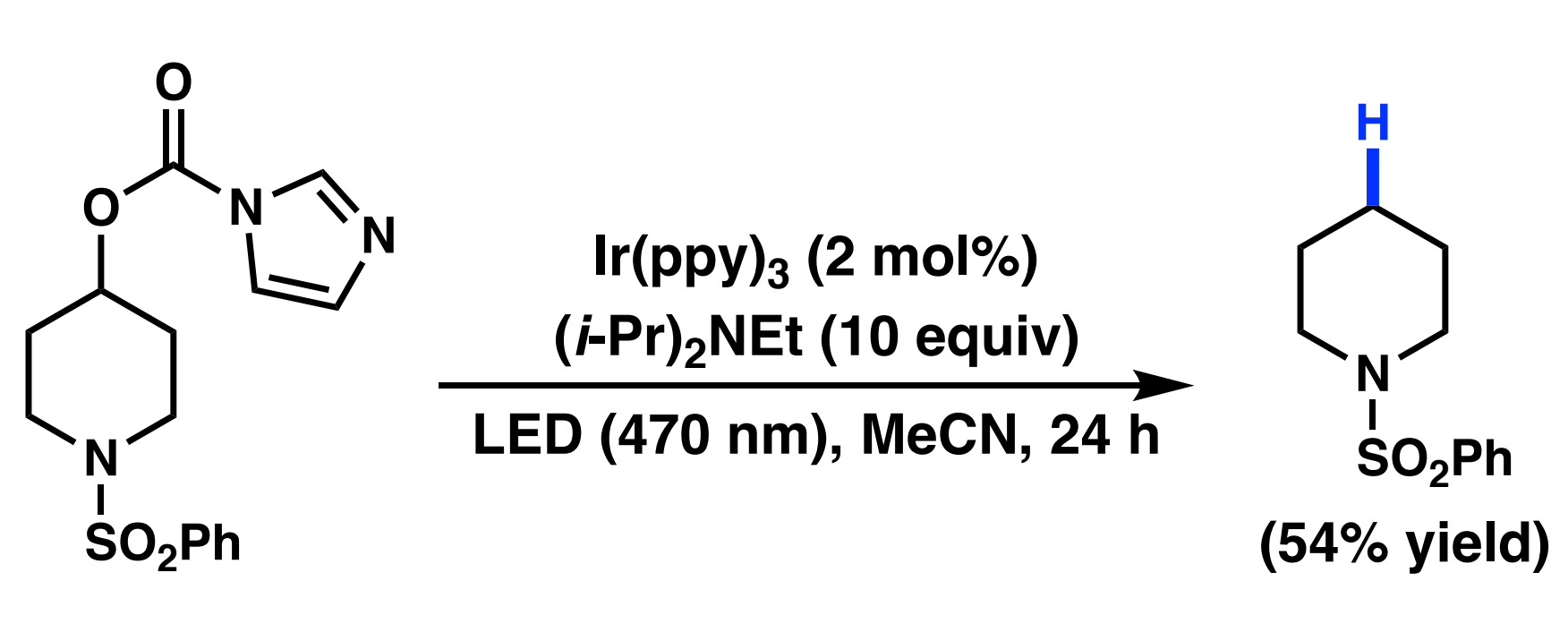

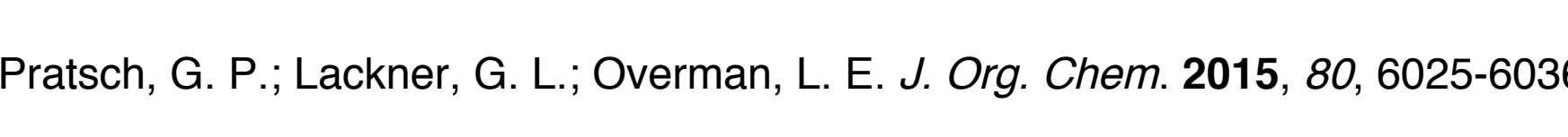

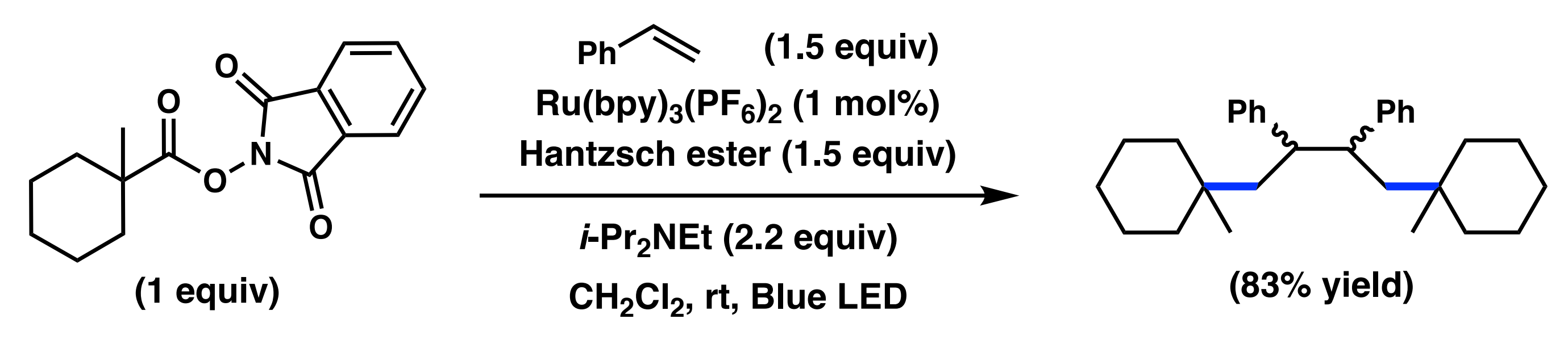

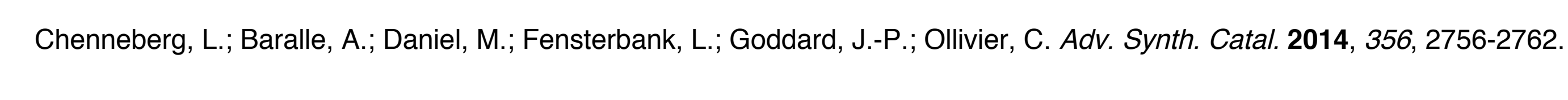

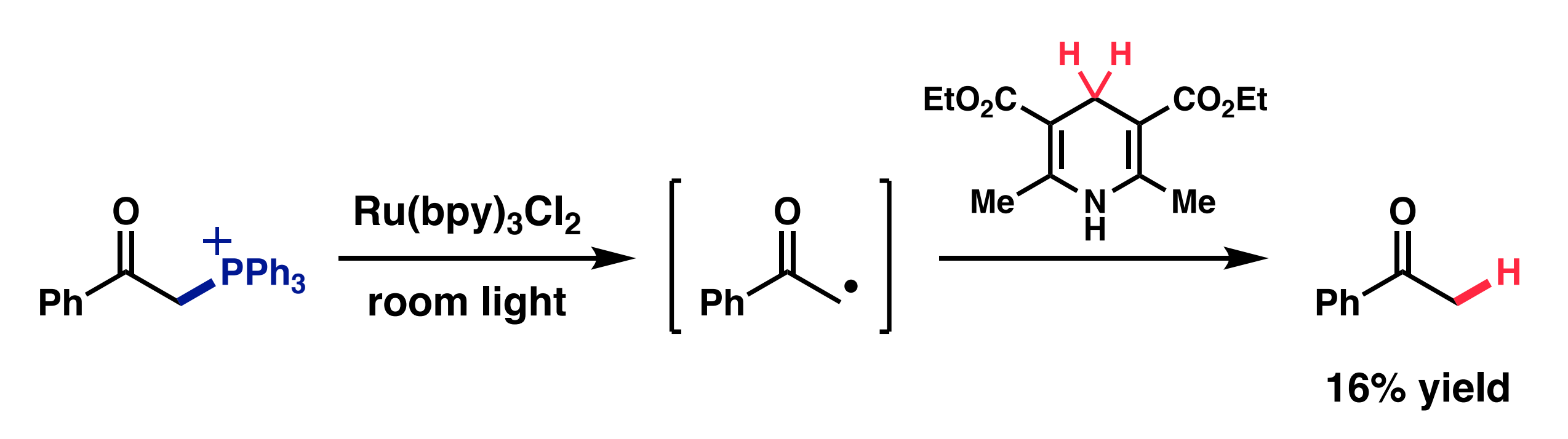

Carbon-Phosphorous radical homolytic cleavage has yet to be thoroughly investigated and it opens a new scope of possible traceless activation groups.

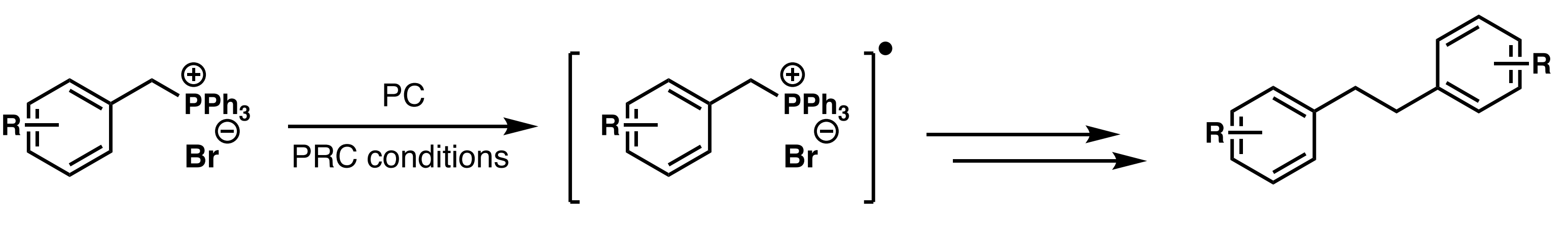

\section{Preliminary Experiments}

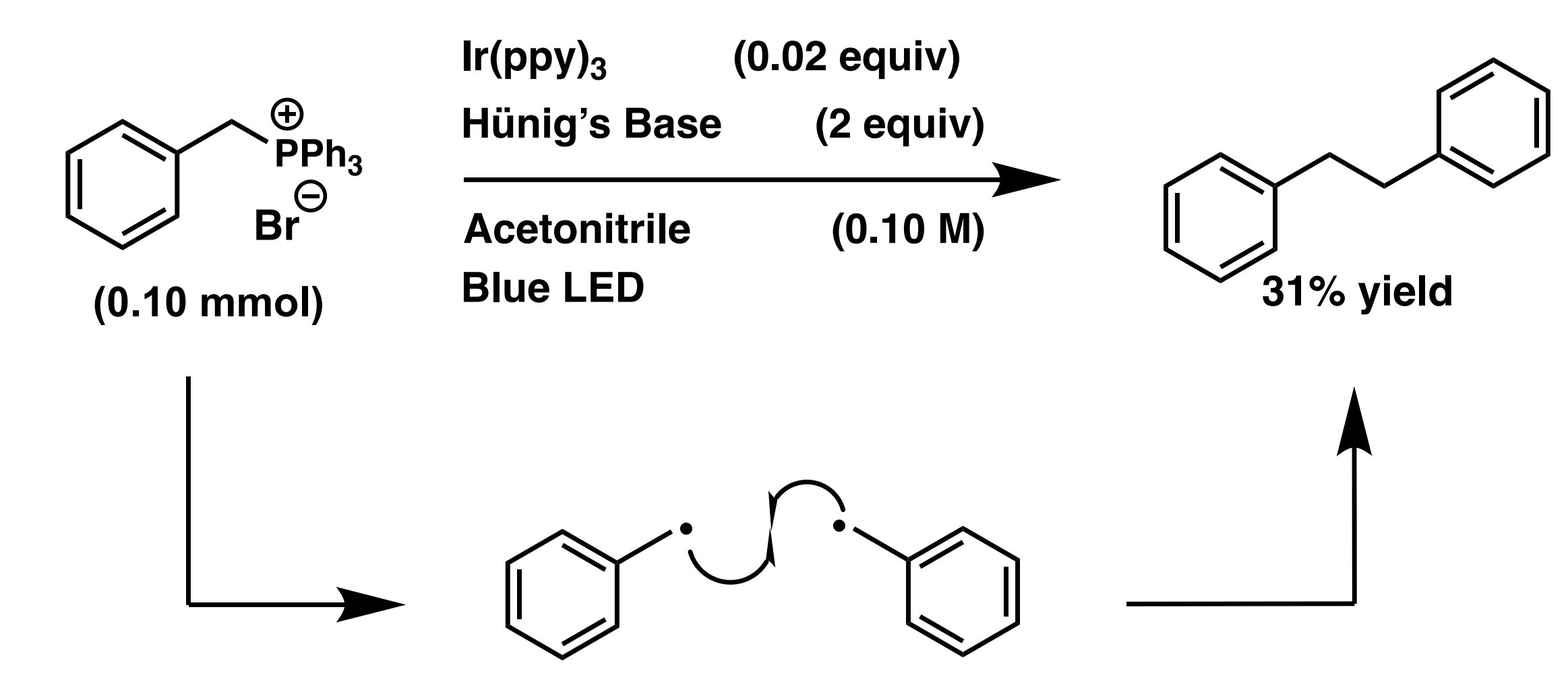

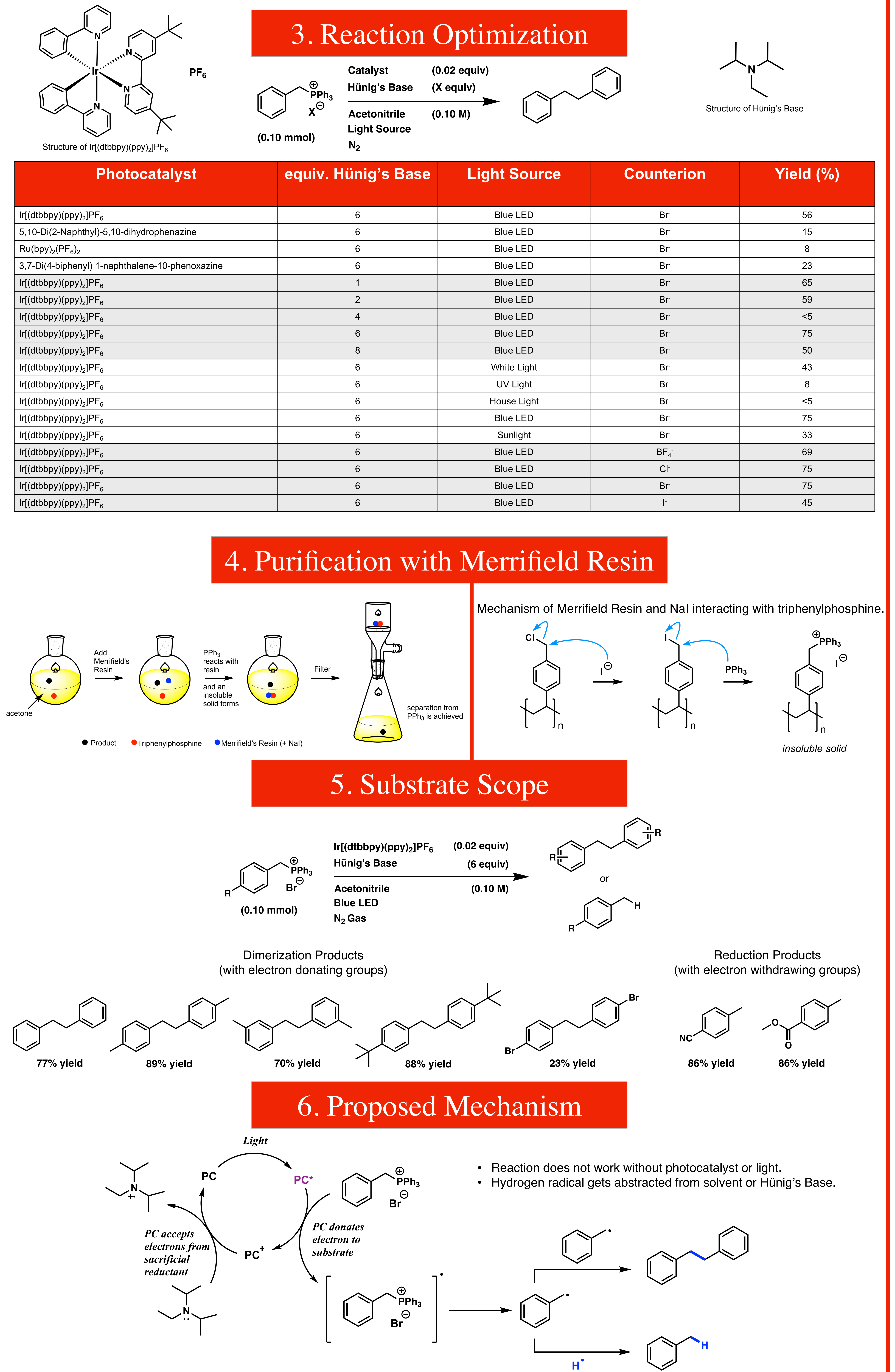

7. Natural Product

Brittonin A
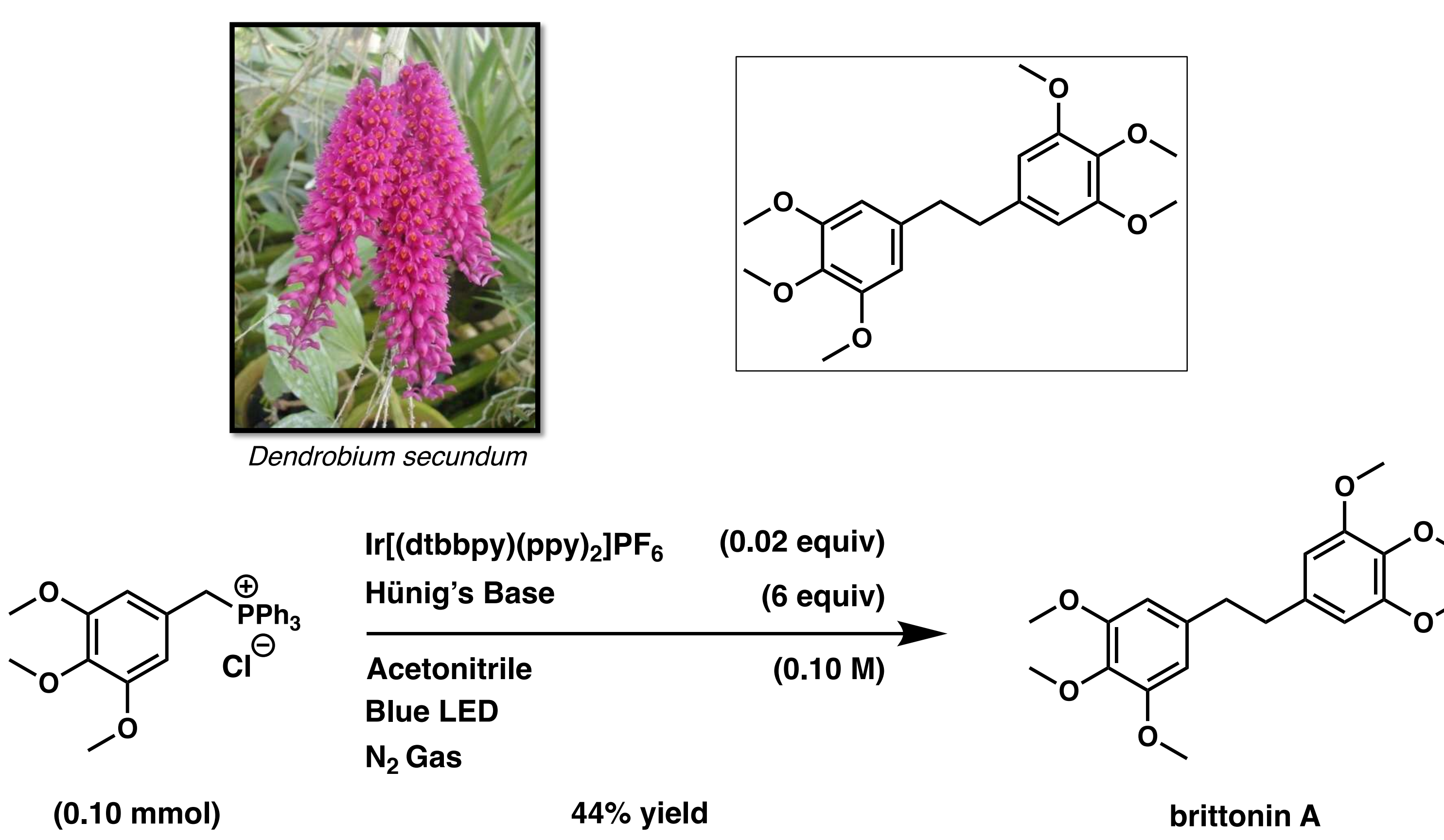

8. Reactivity of Benzyl Bromide

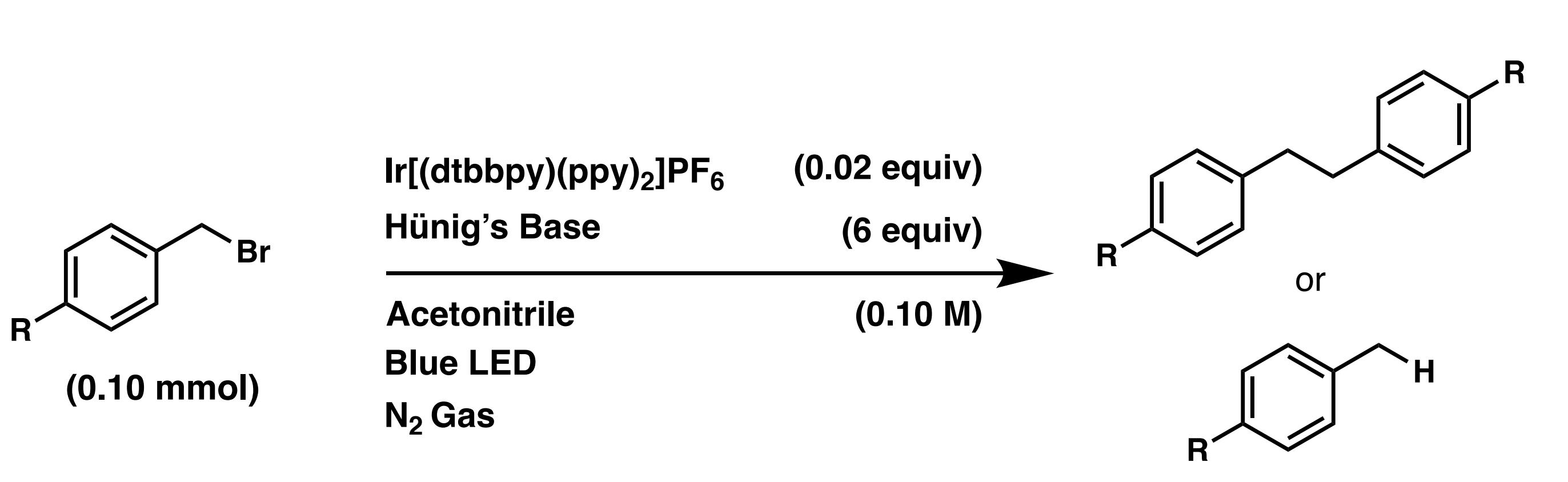

Electron Withdrawing Group Substrates Electron Donating Group Substrates

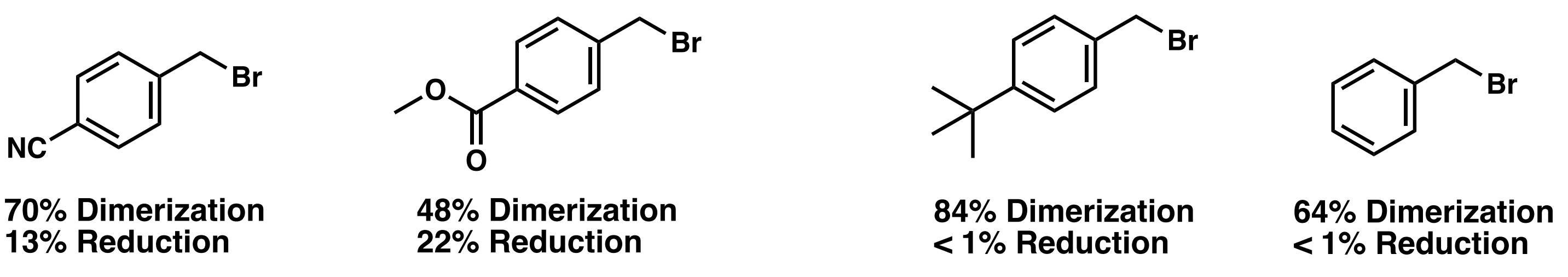

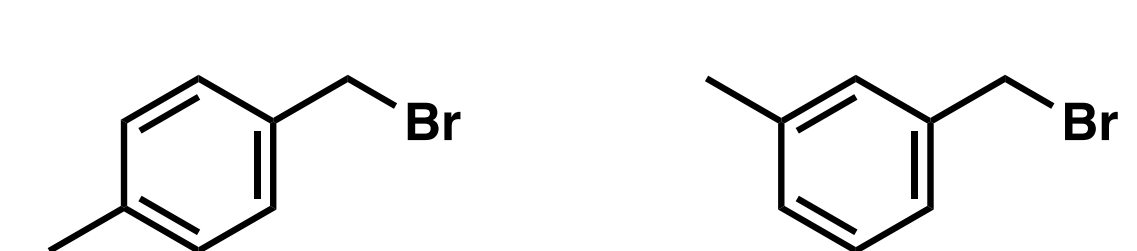

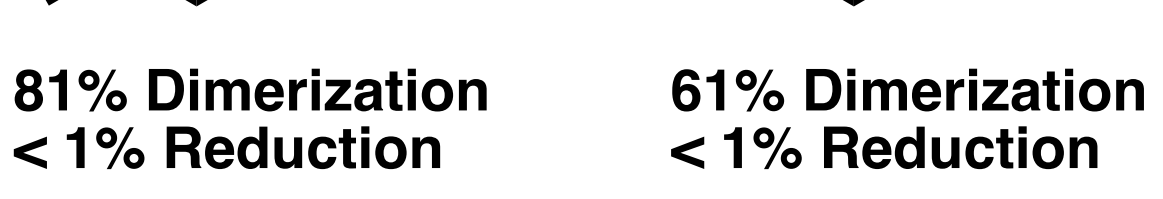

\section{. Conclusions}

Substrates with electron withdrawing groups tend to favor a reduction reaction.

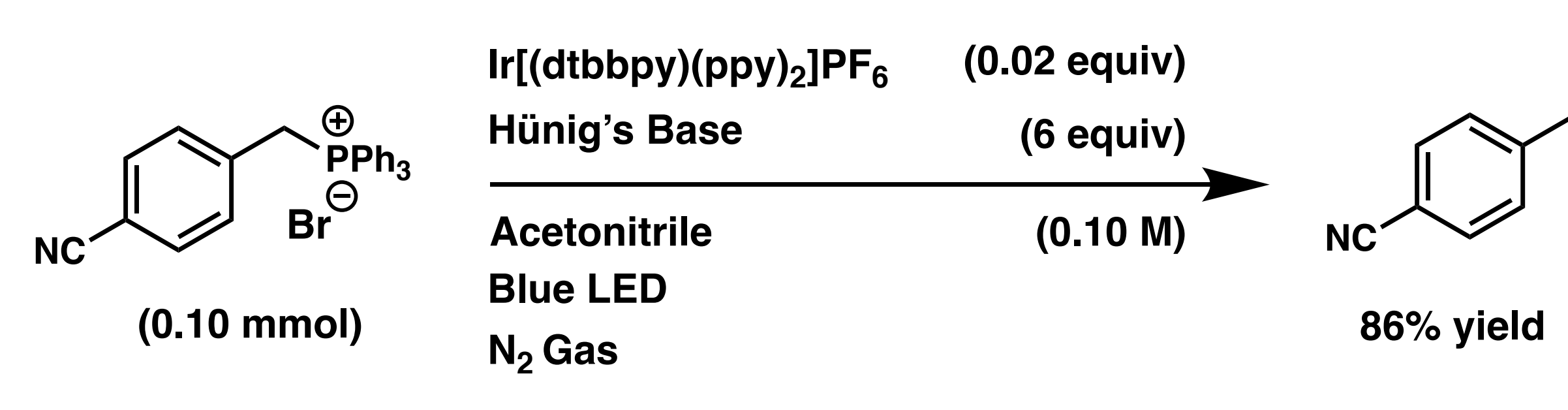

Substrates with electron donating groups favor a dimerization reacion.

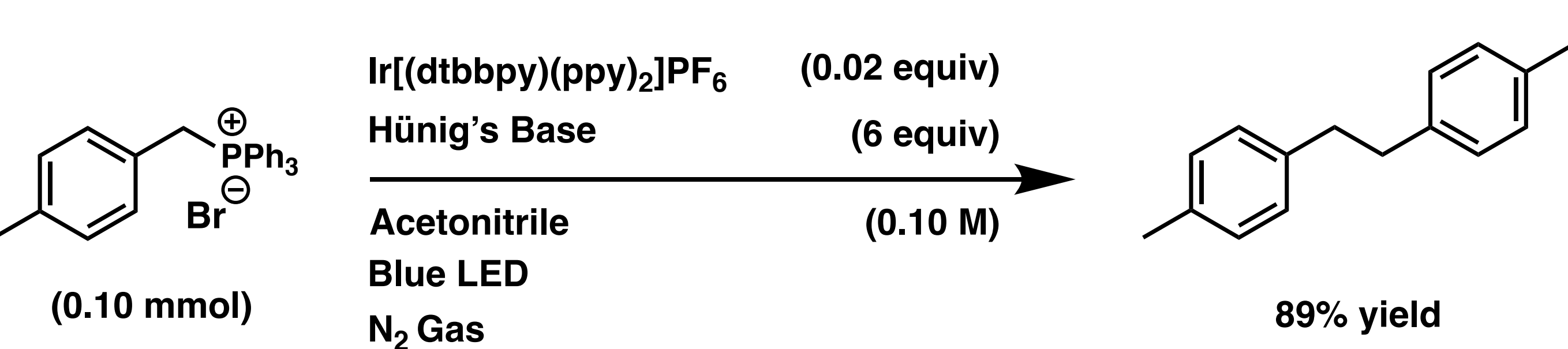

The benzyl bromide substrates with electron withdrawing groups performed both reduction and
dimerization reaction while the triphenylphosphonium salt substrates tended to only do the reduct - The The benzyl bromide substrate with the electron donating groups tended tor
dimerization amounts than the triphenylphosphonium salt substrates.

\section{Acknowledgements}

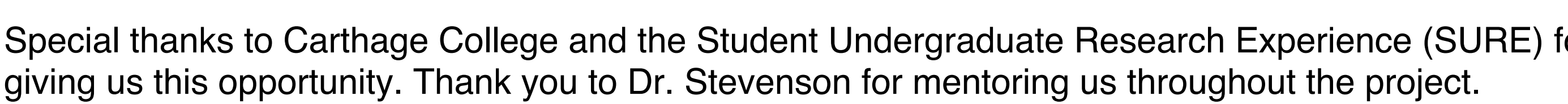

